\title{
NOCTURNAL AND DIURNAL TRENDS OF SURFACE URBAN HEAT ISLAND INTENSITY: A SEASONAL VARIABILITY ANALYSIS FOR SMART URBAN PLANNING
}

\author{
K. Dutta ${ }^{1,}$, D. Basu ${ }^{2}$, S. Agrawal ${ }^{3}$ \\ ${ }^{1}$ GIS Cell, Motilal Nehru National Institute of Technology Allahabad, Prayagraj-211004, Uttar Pradesh, India - \\ rgi1604@mnnit.ac.in \\ ${ }^{2}$ Department of Civil Engineering, Motilal Nehru National Institute of Technology Allahabad, Prayagraj-211004, Uttar Pradesh, \\ India - basud@mnnit.ac.in \\ ${ }^{3}$ GIS Cell, Motilal Nehru National Institute of Technology Allahabad, Prayagraj-211004, Uttar Pradesh, India- \\ sonam@mnnit.ac.in
}

Commission V, WG V/7 \& Commission IV, WG IV/6

KEY WORDS: Urban Heat Island, Impervious Surface Area, Landsat, In-situ Data, Land Management

\begin{abstract}
:
Land management in the limited environment of city regions with immense population pressure is a challenging task. To achieve the goal of sustainable smart cities, reliable spatial information needs to be incorporated in land governance policies. In this study, Landsat 8 satellite bands were processed to derive the land use characteristics which are causing the development of urban heat islands at certain locations. To assess the prolonged effects of heat-trapping in cities, night time temperature data was obtained through in-situ data collection with error within $1^{\circ} \mathrm{C}$. Much higher intensity of urban heat island was observed during the night. The maximum increase of $1.67^{\circ} \mathrm{C}$ was noted from day to night temperature for the same heat island. Seasonal analysis between winter and summer months was also carried out. The results suggested that for both day and night summer months produced more critical heat islands with maximum intensity up to $3.48^{\circ} \mathrm{C}$; while in winter the heat island intensity did not exceed $2.18^{\circ} \mathrm{C}$. Through comparative analysis between two cities with varying extent, urbanization and population pressure, it was observed that the maximum intensity of day time temperature was greater in a bigger city and heat islands were less fragmented. Heat islands covered an area of $10.39 \mathrm{~km}^{2}$ over Prayagraj and $28.29 \mathrm{~km}^{2}$ area of Kolkata. The temperature patterns obtained during day and night were statistically validated with the index of impervious surface area, at the significance level of $\alpha_{0.05}$.
\end{abstract}

\section{INTRODUCTION}

Land provides ecosystem functions and vital socio-economic resources to society. Unplanned urban development often negatively affects land resources and the local environment (Fasona and Omojola, 2009; Grover and Singh, 2015). Certain high risk and hazardous locations develop due to a lack of sustainable land governance. Planners hence, need to propose effective land management techniques, while considering both physical characteristics of land and urban land use pattern.

Location based information is the key to visualize the current scenario of cities where social welfare is under threat. Remote sensing techniques are most suited to capture this type of spatial information over broad areas. Satellite imageries can be processed to generate maps and from these maps, quantitative data on urban land use patterns can be obtained (Pauleit et al., 2005; Vanderstraete et al., 2006; Weng, 2001). The sprawl of congested impervious surfaces and scarcity of vegetation disturbs environmental sustainability. Another challenge to urban sustainability is caused by the formation of the Urban Heat Islands (UHI). These are locations with a relatively higher temperature than surrounding rural neighborhood (Oke, 1976). The presence of impervious surfaces, combustion activities and lack of green areas are major causes behind UHI formation. The day time temperature values are influenced by albedo and surface characteristics. Night time UHI formation occurs due to high concentration of anthropogenic activities in congested urban areas and prolonged heat-trapping at such locations. Such pockets of city regions act as high risk areas because UHI formation has several negative impacts like increasing health risks, consumption of more power, scarcity of resources and trapping of pollutants (Kolokotsa et al., 2009; Rossi et al., 2016; Tan et al., 2010). Land governance will fall short in achieving smart urban goals that work without considering the critical locations of heat islands.

The focus of this study was to analyze the driving forces resulting in land use change patterns and their effects on local temperature. The study is performed on two major cities of India, Prayagraj and Kolkata. These two cities are undergoing different levels of urbanization. Local temperature profiling was performed in both study areas. Day time UHI was mapped with satellite data and the night time temperature data was collected through field surveys. Handheld temperature sensors were utilized for in-situ data collection. The overall Land Use Land Cover (LULC) patterns for both cities were matched with the spatial pattern of UHI. Among urban land covers, the presence of concrete surfaces affects the Land Surface Temperature (LST) pattern the most. Therefore, Fractional Vegetation Cover (FVC) and Impervious Surface Area (ISA) indices were derived to statistically validate the spatial pattern of UHI formation. Seasonal analysis was performed in Prayagraj to find out the season with a comparatively more critical UHI scenario.

Most of the UHI studies are carried out by using satellite data They quantify and analyze day time UHI (Weng et al., 2019; Zhao et al., 2010). Some of them also studied the night time UHI effect (Soltani and Sharifi, 2017; Tiangco et al., 2008). To assess the thermal characteristics of the city center, the resolution of night time satellite data was not satisfactory. Therefore, to map the night LST for this study, in-situ data collection was carried out. The objective of the study was to compare diurnal and

* Corresponding author 
nocturnal UHI patterns for two cities with considerable differences in size, population and infrastructural development. Also, the seasonal UHI intensity was assessed. Spatial patterns of UHI, for both day and night, were validated with location based land cover characteristics. All areas were identified where smart urban designs need to be implemented. Thus, the study aimed to demonstrate the utilization of remote sensing and field survey in environment protection and land management policies, by obtaining thermal and land cover data.

\section{DESCRIPTION OF STUDY AREA}

The study included the city of Prayagraj belonging to the Indian state of Uttar Pradesh. Situated at the confluence of Ganga, Yamuna and Saraswati rivers, it is one of the oldest cities in India. Currently, Prayagraj witnessed drastic growth in built-up, especially during the occasion of Ardh Kumbh Mela. The spread of impervious surfaces was rapid, which might have resulted in the development of thermal hotspots. As the study deals with urban heat islands, only the main city region of Prayagraj was taken, which extends from $25^{\circ} 24^{\prime} \mathrm{N}$ to $25^{\circ} 30^{\prime} \mathrm{N}$ and from $81^{\circ} 47^{\prime} \mathrm{E}$ to $81^{\circ} 53^{\prime} \mathrm{E}$. This study region covers an area of $66.54 \mathrm{~km}^{2}$. To compare the results with another city of greater extent and urban development, Kolkata was taken. Kolkata is the capital of the Indian state of West Bengal and is one of the major cities of eastern India. This city is also located beside the river Ganga. As the urban area in Kolkata covers its entire district, the whole of Kolkata district was considered for UHI analysis. Kolkata extends from $22^{\circ} 27^{\prime} \mathrm{N}$ to $22^{\circ} 37^{\prime} \mathrm{N}$ and from $88^{\circ} 14^{\prime} \mathrm{E}$ to $88^{0} 28^{\prime} \mathrm{E}$. The areal extent is $188.06 \mathrm{~km}^{2}$. Both the study areas are shown in Figure 1.

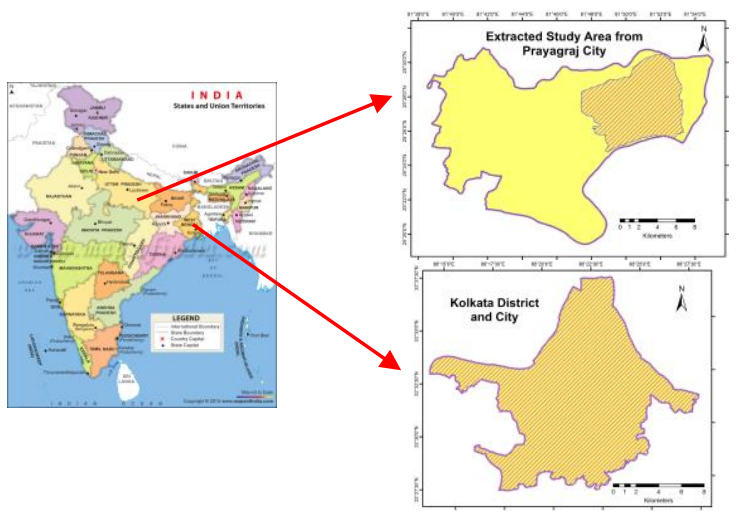

Figure 1. Location and extent of study areas

\section{DATA CHARACTERISTICS}

\subsection{Remote Sensing and Map Data}

Satellite images of Landsat 8 with OLI/TIRS (Operational Land Imager \& Thermal Infrared) sensors, were obtained from U.S. Geological Survey. The thermal band was used for day time LST map generation. Maps of land cover characteristics were derived from other band combinations. To focus on the current UHI and land use scenario, summer and winter season images of the year 2019 were taken for Prayagraj. For Kolkata, satellite images of the year 2018 summer season were utilized as in-situ temperature data collection was carried out at the same time. Other than satellite images, Survey of India topographical maps were utilized as reference data in this study.

\subsection{In-situ temperature measurement}

To generate the night time LST pattern, temperature data was collected. Handheld devices were used for data collection, where Bme 280 Digital Sensor Module Kg501 was mounted. The device had accuracy of $\pm 1^{\circ}$ Celsius. Temperature measurements were started after $11 \mathrm{pm}$ for each sampling schedule; because by this time, the anthropogenic activities nearly stop. Hence, the observed temperature pattern reflected locations with a high rate of heat-trapping.

\section{METHODOLOGY}

The procedures applied to achieve the results are shown by the flowchart in Figure 2.

\subsection{Night Time LST Pattern by In-situ Temperature Measurement}

A total of 30 data points, fairly distributed over the study area were selected for Prayagraj and they are shown in Figure 3. The data was collected on one cloud free day in the first week of April 2019 , representing summer season and on one cloud free day in the first week of January 2019, as winter season. The extensive LULC study was performed through field survey and image analysis. Hence, it was made sure that the points cover different types of land use classes. Another set of 20 points were decided for error checking, after interpolation. Night time LST maps were prepared by interpolation. In this case, Ordinary Kriging was used as the interpolation technique.

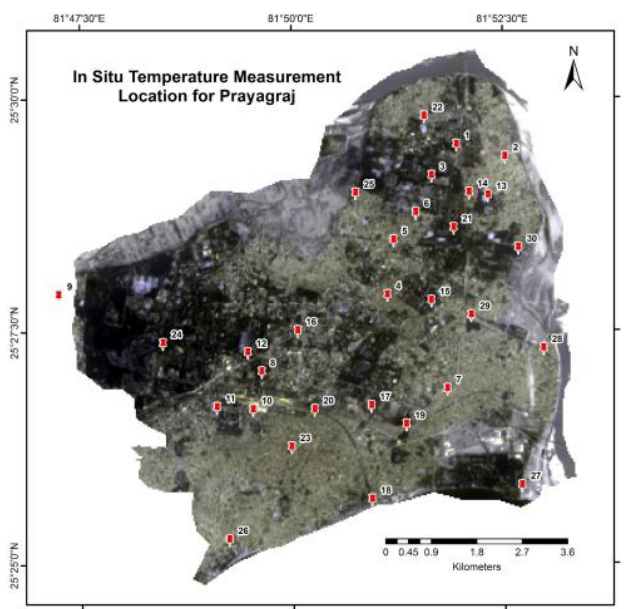

1. MNNIT Campus, 2. Teliarganj, 3. Cantonment, 4. Old Katra, 5. Mamfordganj, 6. George Town, 7. Railway Colony, 8. Leader Road 9. Madhuvan Vihar, 10. Khusrobagh Road, 11. Polo Ground, 12. Allahabad High Court, 13. Ishwar Saran College, 14. Kushwaha Nagar, 15. University Park, 16. Civil Lines, 17. Allahabad City, 18. Yamuna Bank Road, 19. Bairahana, 20. Amar Deep Hospital, 21. Cantonment Road, 22. Rasulabad, 23. Mutthiganj, 24. Dhoomanganj, 25. Kamla Nagar, 26. Karela Bagh, 27. Kumbh Area, 28. Bakshi Nagar, 29. Saket Hospital, 30. Om Gaytri Nagar

Figure 2. Distribution of locations in Prayagraj for in-situ temperature measurement at night 


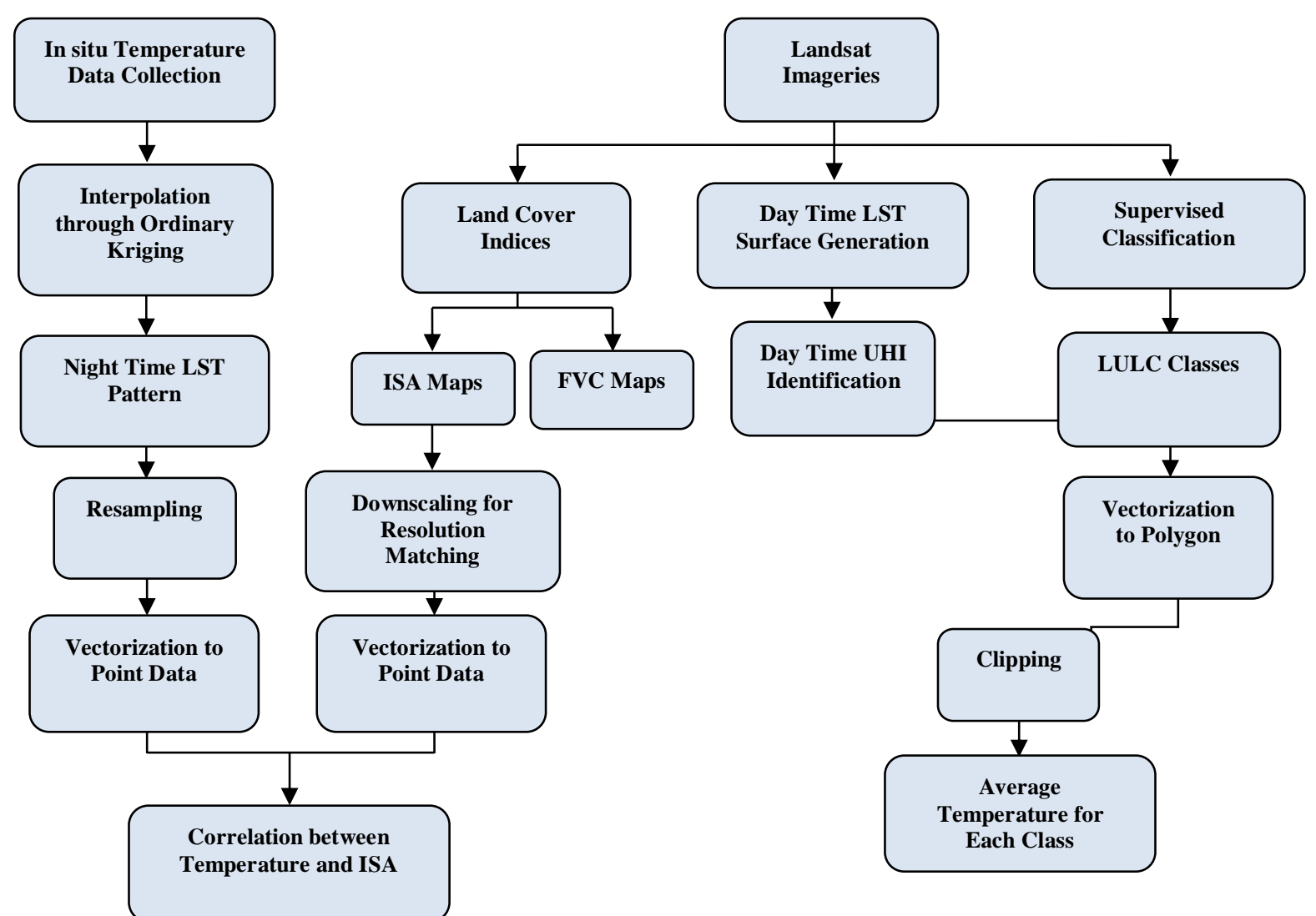

Figure 3. Flow chart of methodology

Kriging provides more reliable interpolation as specific values of spatial autocorrelation of sample points are considered (Setianto and Triandini, 2013; Van Beers and Kleijnen, 2003). After generating a spatial LST profile, the errors for interpolation were checked. Temperature values obtained directly by in-situ measurements at those 20 points of checking were compared with LST values obtained after interpolation, at the same points. The value of Root Mean Square Error (RMSE) was computed to assess the quality of night time LST profile. The highest temperature pockets present at night time LST profile were identified as UHI locations.

In the case of Kolkata, a similar approach was adopted. On a cloud free night in the first week of April, 2018 field data collection was carried out. A total of 28 points were used for night time temperature data collection as shown in Figure 4. A small scale previous field study indicated summer to be the critical season for UHI. Hence, only summer temperature of Kolkata was analyzed as a reference to the study in Prayagraj.

\subsection{Day Time UHI Zoning from Satellite Imageries}

Thermal bands of two seasons for Prayagraj and one for Kolkata were processed to generate LST maps. At first, the pixel Digital Numbers (DN) were converted to spectral radiance as per the globalized methods provided by NASA (NASA, 2011). Mono window algorithm was applied to determine the temperature in Kelvin as per the formula outlined by Qin et al., (2001). Lastly, the Kelvin temperature values were converted to the Celsius temperature of the land surface. Each LST map was categorized into five classes, representing zones of very low temperature, low temperature, moderate temperature, high temperature and very high temperature.

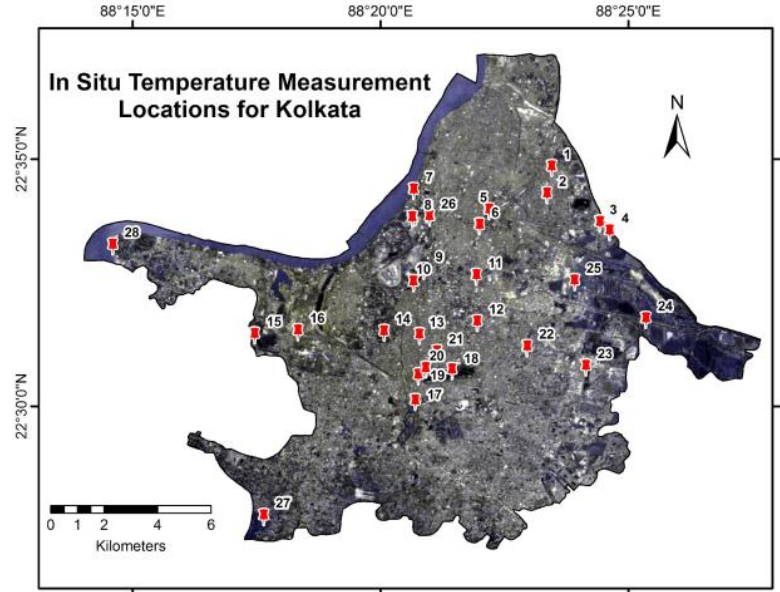

1. Kakurgachi, 2. Phoolbagan, 3. Ragini Theatre, 4. Chingrighata, 5. Sealdah Station, 6. Moulali, 7. Millenium Park, 8. Eden Gardens, 9. Birla Planetorium, 10. Rabindra Sadan, 11. Park Circus, 12. Ballygunge, 13. Jatin Das Park, 14. German Consulate, 15. Taratala, 16. Alipur, 17. Tollygunge, 18. Rabindra Sarovar, 19. Mudiali, 20. Southern Avenue, 21. Deshopriya Park, 22. Kosba, 23. Ruby, 24. Chowbaga, 25. Science City, 26. Dharmatala, 27. Village I, 28. Villagae II

Figure 4. Distribution of locations in Kolkata for in-situ temperature measurement at night

This generalization was done as the images are of different places and seasons and hence showed varying ranges in the LST profile (Dutta et al., 2018). The highest temperature zone was considered an urban heat island. The intensity of $\mathrm{UHI}\left(\mathrm{UHI}_{\mathrm{I}}\right)$ was calculated as the maximum difference between the LST of the heat island and the average LST of the land surface (Zhao et al., 2010). 


\subsection{LULC Categories}

The spatial characteristics of UHI can be explained by the LULC pattern of a city region. LULC maps can be simply developed by processing satellite images (Abd El-Kawy et al., 2011; Punia et al., 2011; Sobrino and Raissouni, 2000). Maximum likelihood supervised classification was applied on stacked satellite imageries. Six classes of land use land cover as, urban, vegetation, water, open land, bare soil and sand were identified for Prayagraj. For Kolkata, the five LULC classes were dense urban, mixed urban, open field, vegetation and water. The UHI locations were matched with the LULC categories to understand the type of land use which are suitable for thermal hotspots. To quantify this, an average temperature of major land use classes were noted for both cities.

\subsection{Validation of UHI with Land Cover Parameters}

The spatial dynamics of urban built up over both cities was used to statistically validate the observed LST pattern. Many researchers have shown the presence of built-up surface and low vegetation concentration leading to the creation of urban heat islands (Connors et al., 2012; Rasul and Ibrahim, 2017). To analyze the cause of heat island formation, Pearson's product moment correlation coefficient between impervious surface area and LST was computed. The analysis was carried out for both day and night at the pixel level, for the entire spatial extension. To generate the ISA map, firstly, FVC map was prepared (Carlson and Arthur, 2000). FVC map was developed using the scaled Normalized difference Vegetation Index. As ISA and FVC vary inversely in urban areas, ISA maps were prepared using the FVC maps. The ISA maps were then downscaled to $100 \mathrm{~m}$ with nearest neighbor resampling. The LST and ISA maps were then vectorized to point files before calculating correlation values.

\section{RESULTS AND DISCUSSION}

\subsection{Night time LST of Prayagraj}

The night time LST of Prayagraj for winter and summer months are shown in Figure 5. In winter, only one major heat island can be observed at the centre of the city, around civil Lines area (a). High rate of anthropogenic activities at this place can be the reason behind heat-trapping till late night. The maximum intensity was $2.18^{\circ} \mathrm{C}$. On the contrary, the areas close to river channel were cooled down by land breeze at night. The overall temperature pattern has little variation. In contrast, the night time LST profile of summer depicted much more variation in LST profile. Maximum UHI of $3.48^{\circ} \mathrm{C}$ was observed at the central city region. Four major heat islands were clearly visible. The distinct UHIs were at north the Teliarganj area (a), at east Govindpur residential area (b), at center the Civil Lines area (c) and towards south around Hazrat Ganj (d). Comparing the intensity values with the winter UHIs, it can be said that, in summer nights the problem of heat trapping is more critical. The UHI observed at night, for both seasons, were higher than day time UHI. It showed that certain locations were at high risk even at night. The accuracy of night time field survey was assessed through RMSE between observed and interpolated LST values. In winter the RMSE was $0.40^{\circ} \mathrm{C}$ and in summer the RMSE was $0.84^{\circ} \mathrm{C}$.

\subsection{Day time UHI of Prayagraj}

The day time LST profile and the identified UHI zones in winter, for Prayagraj, have been shown in Figure 6. The UHIs identified by very high temperature zones, were spread all over

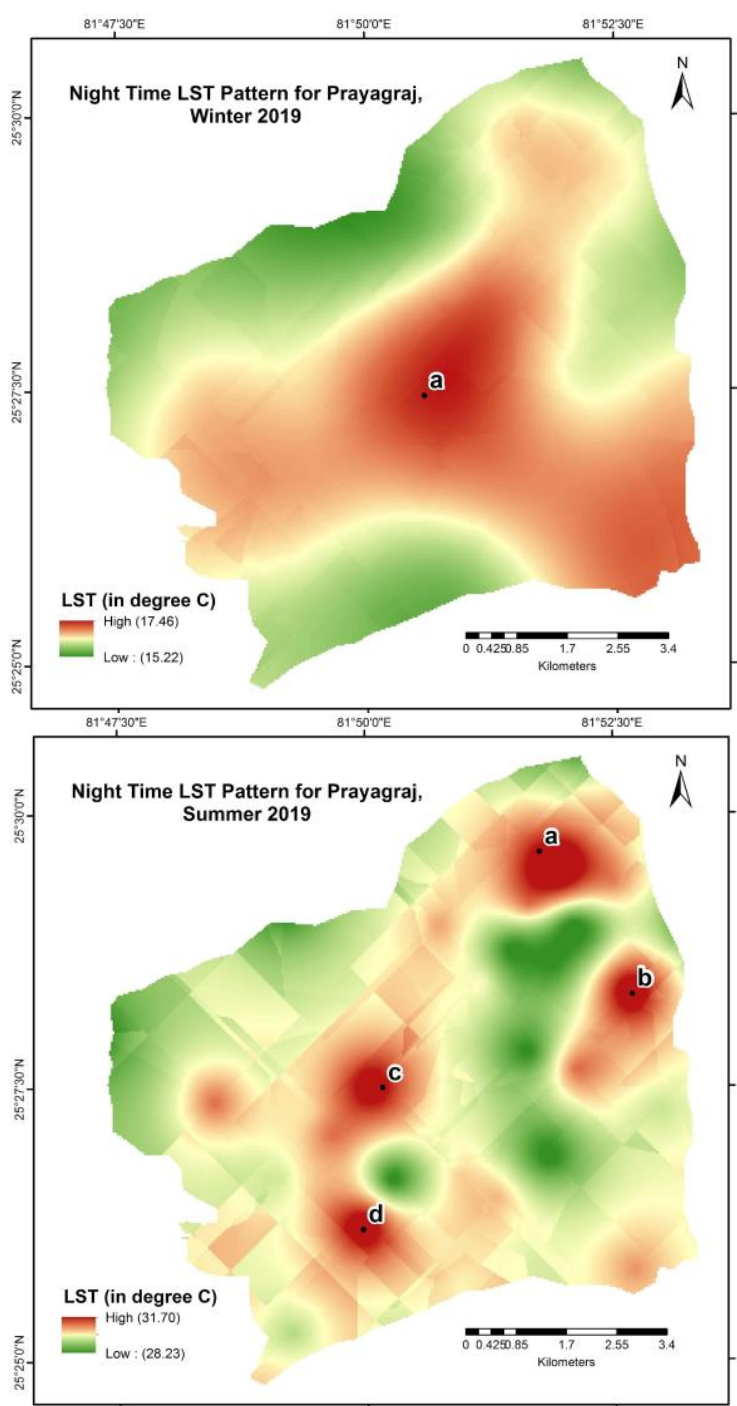

Figure 5. Night time LST profile of Prayagraj for winter and summer, 2019

the city region. Heat islands covered a total area of $9.47 \mathrm{~km}^{2}$ in winter. A major heat island in the north west part, over urban areas of Kamlanagar (a) and Teliarganj can be clearly seen. It was marked with $1.85^{\circ} \mathrm{C}$ of UHI. Towards north, over congested parts of Mumfordganj (b) and Old Katra another heat island was identified. Here intensity of UHI was $1.21^{\circ} \mathrm{C}$. The dense residential area of Govindpur (c) and Rajiv Nagar in the east was a major heat island area with intensity of $1.59^{\circ} \mathrm{C}$. At the center of Prayagraj City, Civil Lines (d) was another UHI with $1.26^{\circ} \mathrm{C}$ intensity. Other distinct UHIs can be found at the southern parts of the city. $2.04^{\circ} \mathrm{C}$ of UHI was marked at the UHI formed near Sangam area (e). Prayagraj Junction (f) and the old commercial zones at its south were other UHIs with $1.7^{\circ} \mathrm{C}$ of intensity. Towards west, a linear pattern $(\mathrm{g})$ of UHI can be found with intensity of $1.81^{\circ} \mathrm{C}$. The linear shape of this heat island was probably due to the high concentration of urban places and anthropogenic activities beside railway line present here.

The summer day time LST and UHI pattern was quite similar to the winter month, for most parts of the city. The patterns are shown in Figure 7. One major difference was the extensive heat island forming over Hazrat Ganj (a), in the southern parts of 


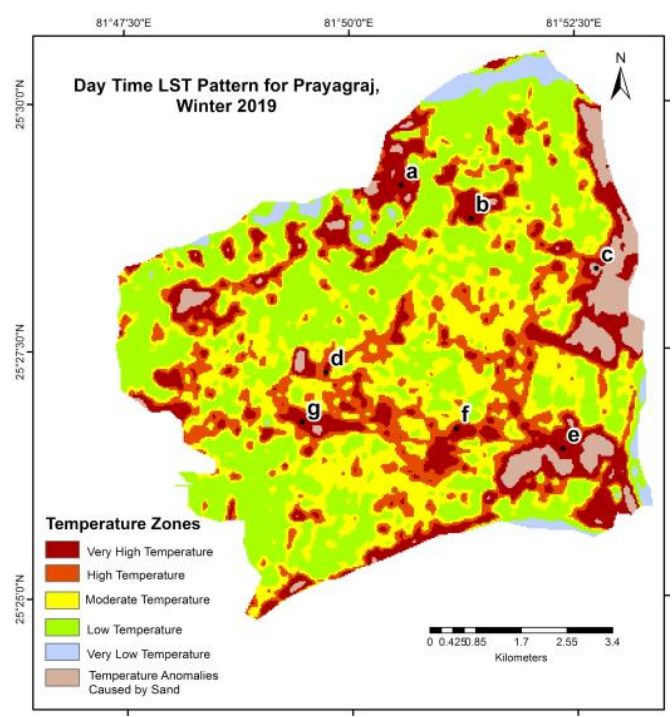

Figure 6. Day time LST and UHI of Prayagraj in winter, 2019

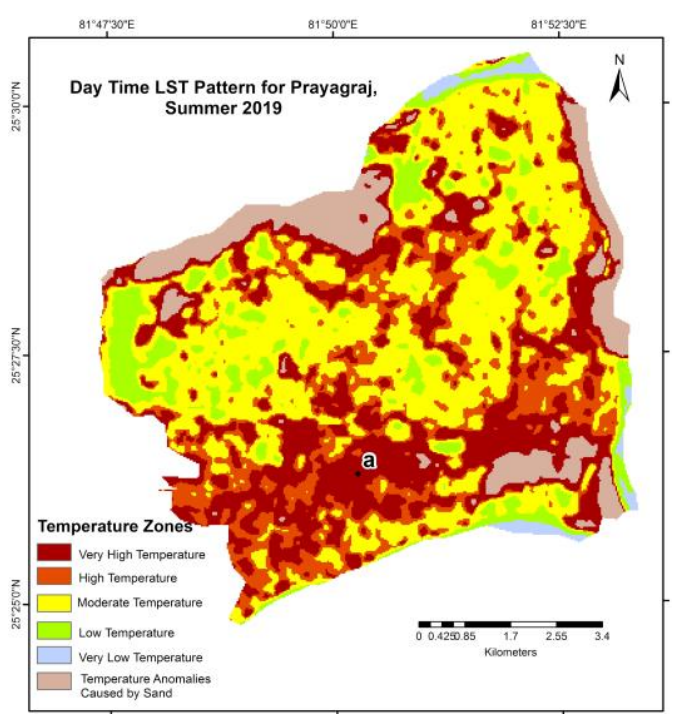

Figure 7. Day time LST and UHI of Prayagraj in summer, 2019

Prayagraj. The UHI cover increased to $10.39 \mathrm{~km}^{2}$, covering $15.61 \%$ of the total area. The UHI in this southern commercial area was $1.99^{\circ} \mathrm{C}$.

\subsection{LULC pattern of Prayagraj}

The land use land cover pattern along with percentage area cover of each category, over Prayagraj is shown in Figure 8. An area of $38.56 \mathrm{~km}^{2}$ was covered by urban built up. In comparison, vegetation was covering only $13.7 \mathrm{~km}^{2}$ area. The LULC pattern explained the spatial characteristics of the LST profile. Extensive built up areas in southern parts, at south east and over central parts match with the UHI locations. The most prominent dense built up was at south, around Hazrat Ganj (a). Comparing with Figure 6 and Figure 7, this area was marked with high temperature in both seasons. In contrast to the urban areas, the patches of vegetated land were all marked with low temperatures. From Figure 6, Figure 7 and Figure 8, it can be observed that the old cantonment area towards north (b), Chandra Shekhar Azad Park (c) at center and at west around Dhoomanganj (d), vegetation was present resulting in low temperature values.

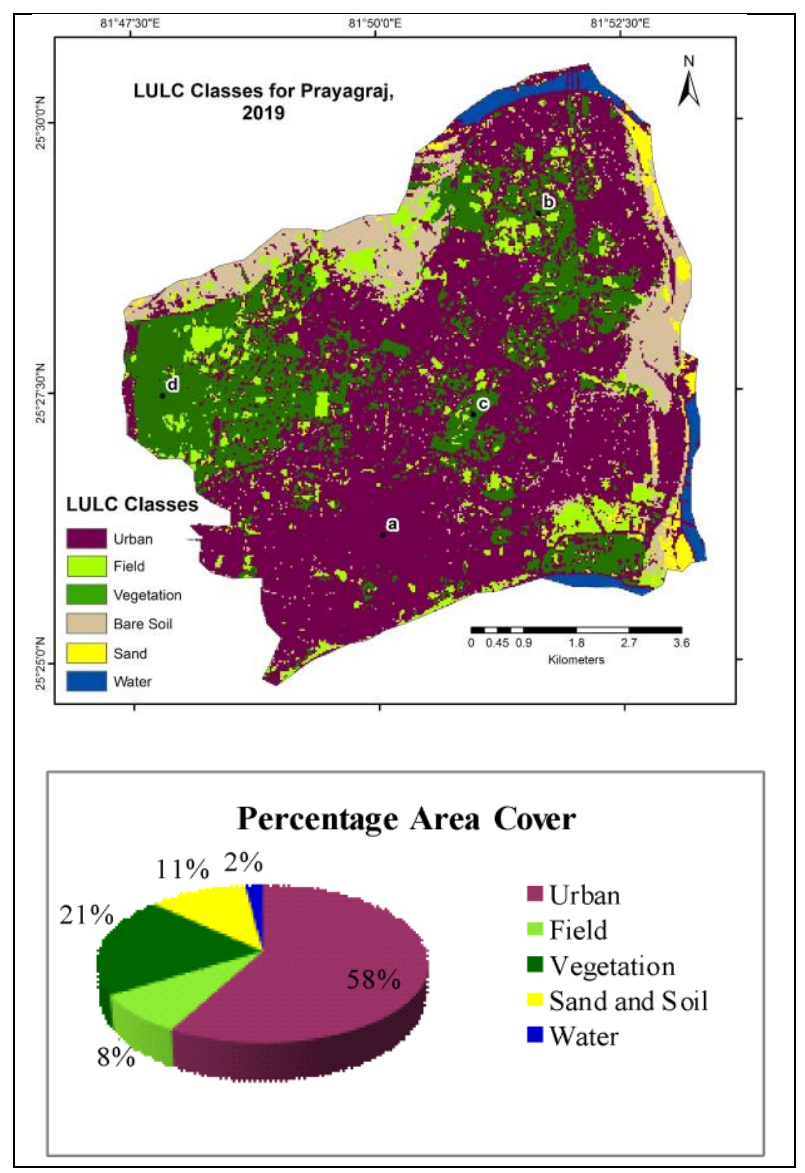

Figure 8. LULC pattern of Prayagraj in 2019

To further understand the effect of land surface characteristics on UHI development, the average temperature of major LULC classes were noted and are listed in Table 1 . As the images were captured in morning, heating in open fields, sand and bare soil was rapid. This is clearly depicted by the high average LST of these classes. Between urban and vegetation classes, the difference in average LST was much higher in summer. The urban built up in summer was $1.21^{\circ} \mathrm{C}$ warmer on an average, than green areas. In winter morning, this difference was $0.09^{\circ} \mathrm{C}$.

It matched with previous results that, summer UHI condition is more critical in this city.

\begin{tabular}{|l|l|l|}
\hline LC Classes & $\begin{array}{c}\text { e Day Time LST in } \\
\text { Winter }\end{array}$ & $\begin{array}{c}\text { e Day Time LST in } \\
\text { Summer }\end{array}$ \\
\hline Urban & $17.8^{0} \mathrm{C}$ & $34.1^{0} \mathrm{C}$ \\
\hline Field & $18.3^{0} \mathrm{C}$ & $35.3^{0} \mathrm{C}$ \\
\hline Vegetation & $17.7^{0} \mathrm{C}$ & $32.9^{0} \mathrm{C}$ \\
\hline Soil and Sand & $18.7^{0} \mathrm{C}$ & $35.8^{0} \mathrm{C}$ \\
\hline
\end{tabular}

Table 1. Average LST of major LULC classes

\subsection{Impact of impervious surface on LST pattern}

To map the major land cover parameter of built up, firstly, FVC map was prepared. Both the FVC and ISA maps are shown in Figure 9. Urban built up identified by the ISA map matched with the spatial pattern of urban class from Figure 8. The FVC map showed presence of vegetation in areas of low built up. 


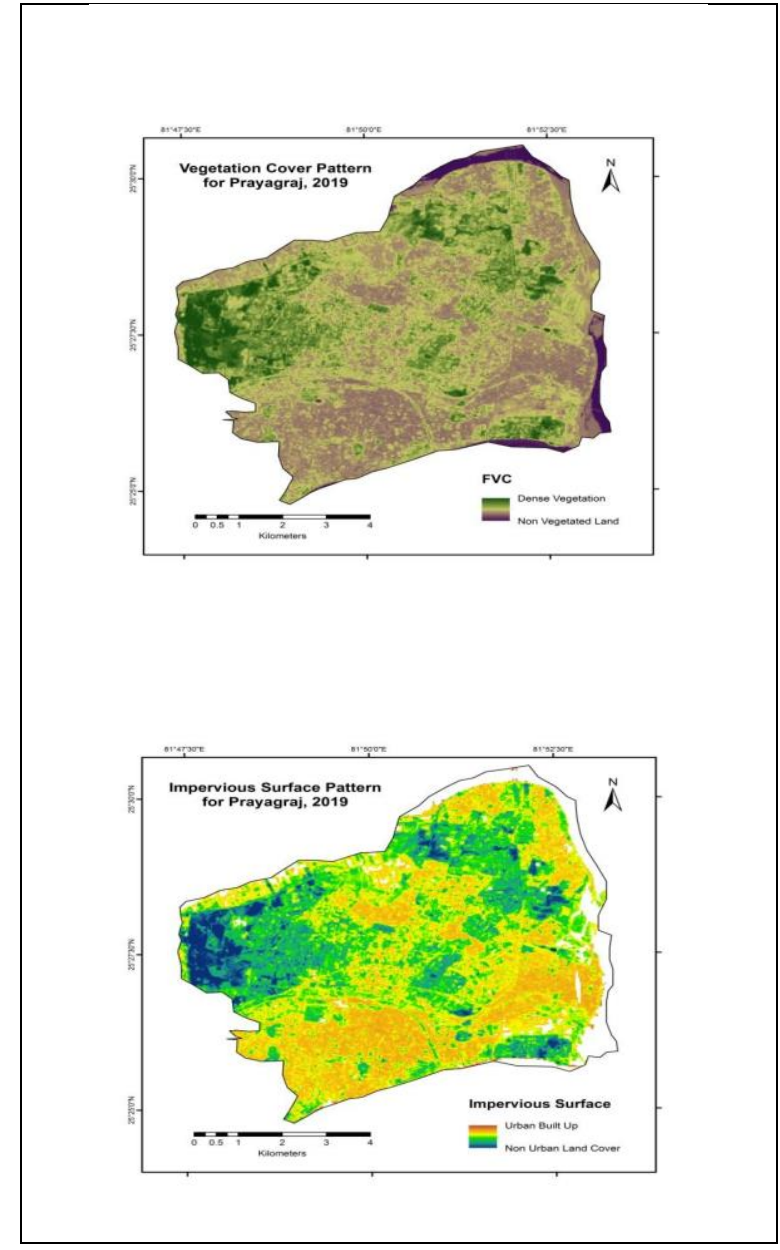

Figure 9. FVC and ISA indices for Prayagraj, 2019

The effect of built up surfaces on LST pattern were analyzed using correlation coefficients. The correlation values between the parameters are listed in Table 2. The values suggested at significance level $\alpha_{0.05}$, that urban sprawl was causing the rise of heat islands at certain locations. Places with dense built-up were resulting in UHI formation.

\begin{tabular}{|c|c|c|c|c|}
\hline Parameters & $\begin{array}{c}\text { Day } \\
\text { Winter }\end{array}$ & $\begin{array}{c}\text { Night } \\
\text { Winter }\end{array}$ & $\begin{array}{c}\text { Day } \\
\text { Summer }\end{array}$ & $\begin{array}{c}\text { Night } \\
\text { Summer }\end{array}$ \\
\hline ISA-LST & 0.245 & 0.485 & 0.664 & 0.588 \\
\hline
\end{tabular}

Table 2. Correlation coefficients between ISA and LST

\subsection{Night time LST of Kolkata}

The temperature data collected in summer, 2018 was interpolated to generate the night time LST map for Kolkata. The map is shown in Figure 10. The LST pattern depicted the presence of one major heat island at central parts of Kolkata. The heat island was present on the central business district (a) of the city. The rate of anthropogenic activities is very high over this zone, leading to the UHI problem at night. The maximum intensity of UHI noted here was $2.43^{\circ} \mathrm{C}$.

\subsection{Day time UHI of Kolkata}

The summer day time LST and the UHI zones for Kolkata are shown in Figure 11. Overall heat islands covered $28.29 \mathrm{~km}^{2}$ area. While in case of Prayagraj only the central commercial urban area was considered, for Kolkata entire district was taken

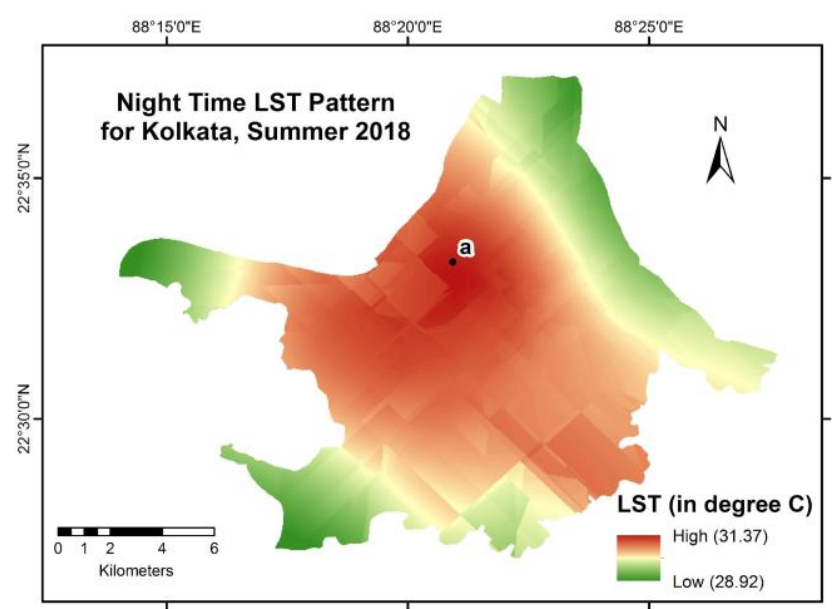

Figure 10. Night time LST profile of Kolkata for summer, 2018

for the study. Still the percentage cover of $15.04 \%$ by UHI was similar to that of Prayagraj City. It shows the urbanization in Kolkata is widespread and problem of UHI is spread over a greater extent. Among the major heat islands observed in day, one was towards north around Dharmatala - Sealdah Station area (a). This is the central business district of Kolkata City and high UHI of $2.47^{\circ} \mathrm{C}$ was noted here. The most distinct UHI was present in the western parts of the city, near Garden Reach (b). Maximum UHI of $4.05^{\circ} \mathrm{C}$ was found here. Other patches of heat islands were over urban centers of Ballygunge, Kalighat, Tollygunge (c) in south. The value of day time UHI in Kolkata was much higher than that observed for Prayagraj. Also the heat islands were less fragmented than UHIs of Prayagraj. In case of Kolkata, larger patches of UHI were distinct.

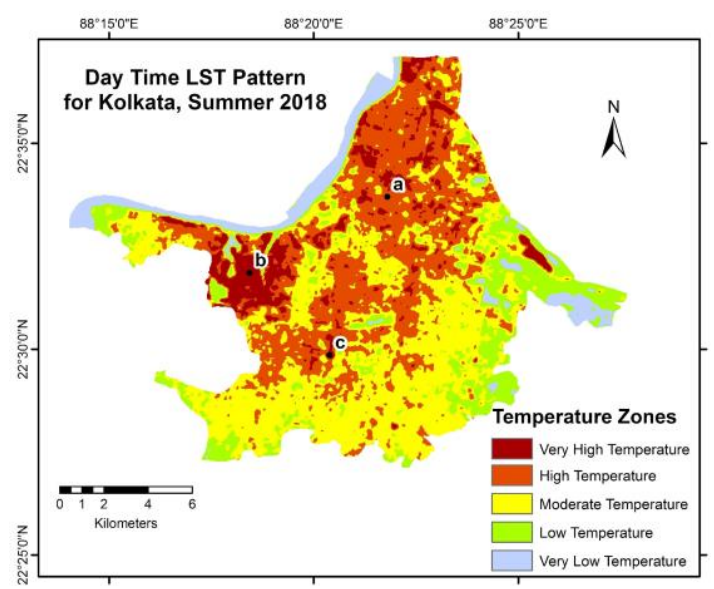

Figure 11. Day time LST and UHI of Kolkata in summer, 2018

\subsection{LULC pattern of Kolkata}

The LULC pattern of Kolkata is shown in Figure 12. The district has a very high percentage of land covered by dense urban and mixed urban. Urban areas covered $114.68 \mathrm{~km}^{2}$ of the city. In contrast, vegetation covers only $7.48 \mathrm{~km}^{2}$ of total area. The LULC pattern explained the spatial distribution of UHIs over Kolkata. Comparing with Figure 11, it is clear that, over urban built up LST is high and UHIs were located at dense urban areas. In contrast to this, the boundary region of the district is covered by vegetation and open fields. These areas have formed low temperature zones. Water bodies also result in cool islands within cities. Towards east the effect of water on creating low temperature zone is very prominent. 

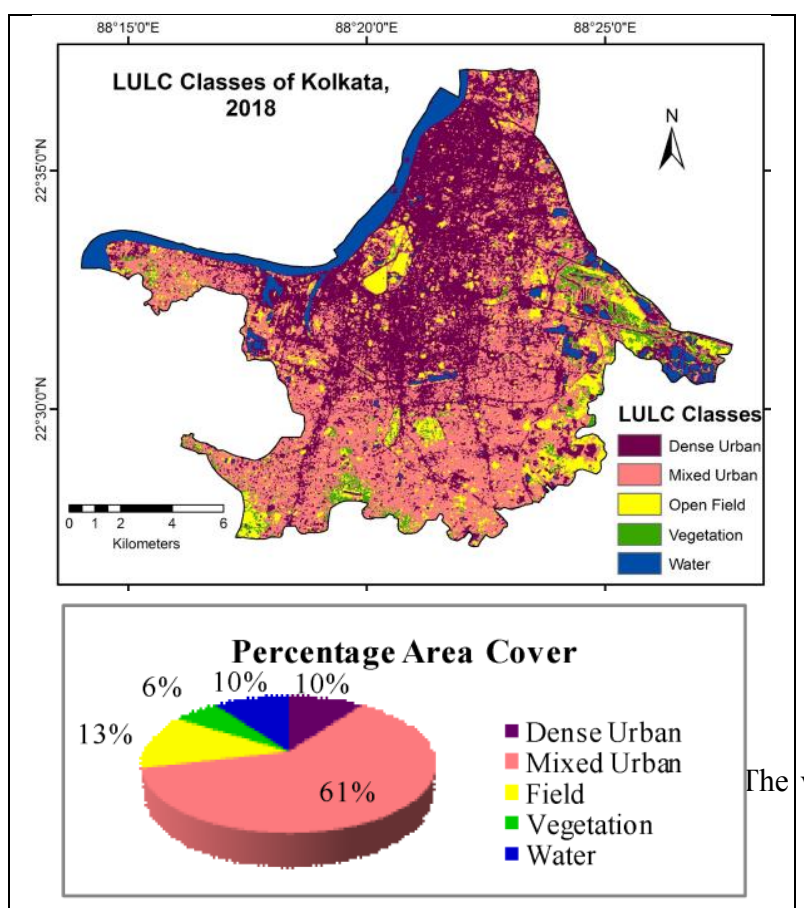

Figure 12. LULC pattern of Kolkata in 2018

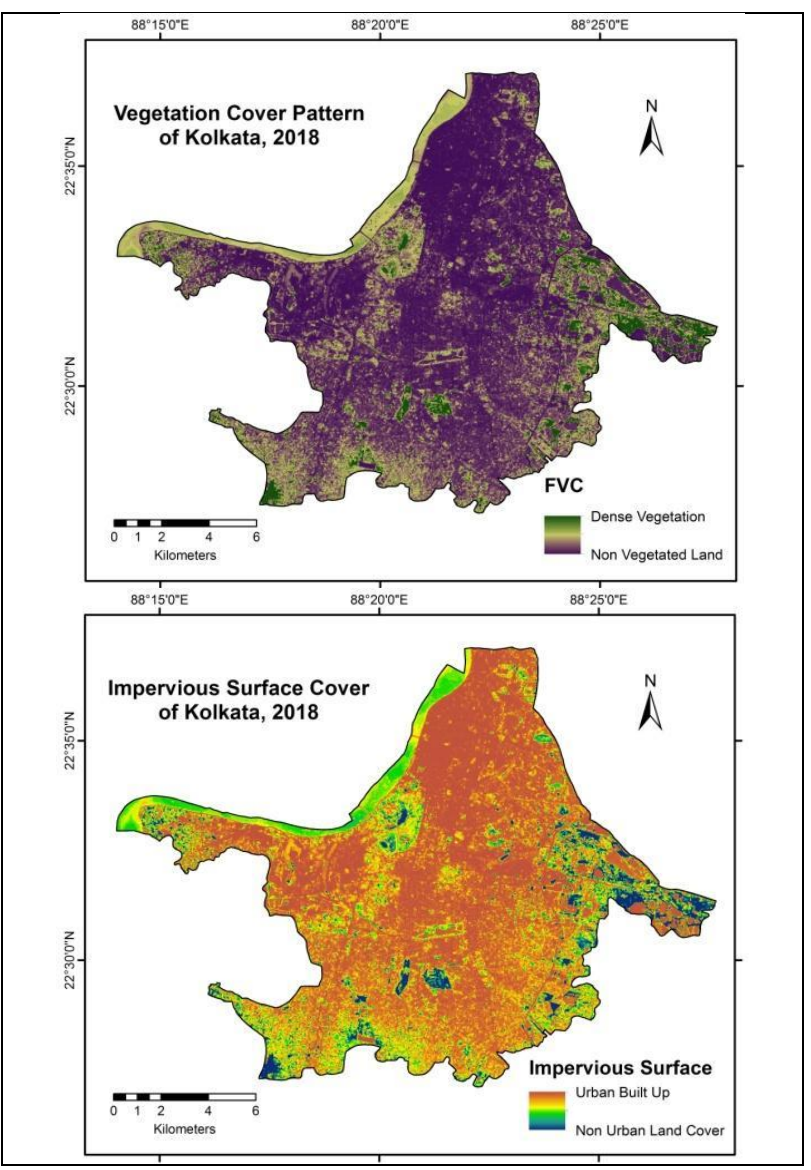

Figure 13. FVC and ISA indices for Kolkata, 2018

The average LST of the LULC classes in Kolkata are listed in Table 3. The average LST values were highest for dense urban areas. The LST was $1.33^{\circ} \mathrm{C}$ higher than the average in vegetated land. The mixed urban and fields also showed higher LST pattern than green areas. These values depicted that, the LST pattern within a city region varies greatly with land cover characteristics.

\begin{tabular}{|c|c|}
\hline LULC Class & Average Day Time LST in Summer \\
\hline Dense Urban & $28.68 \mathrm{C}$ \\
\hline Mixed Urban & $28.46 \mathrm{C}$ \\
\hline Open Field & $28.29 \mathrm{C}$ \\
\hline Vegetation & $27.33 \mathrm{C}$ \\
\hline
\end{tabular}

Table 3. Average LST of major LULC classes

\section{$5.8 \quad$ Impact of impervious surface on LST pattern}

Similar to Prayagraj, ISA map was prepared for Kolkata City from FVC map. These maps are shown in Figure 13. The maps depicted the dominance of built up surface all over Kolkata City. The correlation coefficients between ISA and LST of Kolkata are shown in Table 4.

\begin{tabular}{|c|c|c|}
\hline $\begin{array}{c}\text { Parameter } \\
\mathrm{s}\end{array}$ & Day Summer & Night Summer \\
\hline ISA-LST & 0.656 & 0.417 \\
\hline
\end{tabular}

Table 4. Correlation coefficients between ISA and LST

were significant at $\alpha_{0.05}$. It validated that, urbanization is the cause of heat island growth in case of Kolkata also.

\section{CONCLUSIONS}

The study successfully outlined a set of techniques to identify high risk locations in cities, where sustainability and welfare is challenged. These areas were marked with compact residential or commercial areas with lack of vegetation, resulting in the phenomenon of UHI. For Prayagraj, these locations were listed in Table 5 and for Kolkata city these were listed in Table 6.

\begin{tabular}{|c|c|c|c|c|c|}
\hline $\begin{array}{c}\text { Sl. } \\
\text { No. }\end{array}$ & Locations & $\begin{array}{c}\text { Max. } \\
\mathrm{UHI}_{\mathrm{I}} \text { day }\end{array}$ & $\begin{array}{c}\text { Max. } \\
\mathrm{UHI}_{\mathrm{I}} \text { night }\end{array}$ & ISA & FVC \\
\hline 1 & $\begin{array}{c}\text { Hazrat Ganj- } \\
\text { Kareli-Prayagraj } \\
\text { Junction-Johnston } \\
\text { Ganj }\end{array}$ & $+1.81^{\circ} \mathrm{C}$ & $+3.48^{\circ} \mathrm{C}$ & $\begin{array}{l}+0.19> \\
\text { mean ISA }\end{array}$ & $\begin{array}{c}-0.20< \\
\text { mean FVC }\end{array}$ \\
\hline 2 & $\begin{array}{c}\text { Central Civil } \\
\text { Lines area }\end{array}$ & $+1.09^{\circ} \mathrm{C}$ & $+2.18^{\circ} \mathrm{C}$ & $\begin{array}{l}+0.20> \\
\text { mean ISA }\end{array}$ & $\begin{array}{c}-0.13< \\
\text { mean FVC }\end{array}$ \\
\hline 3 & Old Katra & $+0.93^{\circ} \mathrm{C}$ & $+0.62^{\circ} \mathrm{C}$ & $\begin{array}{l}+0.17> \\
\text { mean ISA }\end{array}$ & $\begin{array}{c}-0.15< \\
\text { mean FVC }\end{array}$ \\
\hline 4 & $\begin{array}{c}\text { Teliarganj- } \\
\text { Phaphamou }\end{array}$ & $+2.16^{\circ} \mathrm{C}$ & $+1.94^{\circ}$ & $\begin{array}{l}+0.17> \\
\text { mean ISA }\end{array}$ & $\begin{array}{c}-0.16< \\
\text { mean FVC }\end{array}$ \\
\hline 5 & Govindpur & $+1.77^{\circ} \mathrm{C}$ & $+1.64^{\circ} \mathrm{C}$ & $\begin{array}{l}+0.18> \\
\text { mean ISA }\end{array}$ & $\begin{array}{c}-0.16< \\
\text { mean FVC }\end{array}$ \\
\hline
\end{tabular}

Table 5. List of high risk locations in Prayagraj

\begin{tabular}{|c|c|c|c|c|c|}
\hline $\begin{array}{c}\text { Sl. } \\
\text { No. }\end{array}$ & Locations & $\begin{array}{c}\text { Max. } \\
\mathrm{UHI}_{\mathrm{I}} \text { day }\end{array}$ & $\begin{array}{c}\text { Max. } \\
\mathrm{UHI}_{\mathrm{I}} \text { night }\end{array}$ & ISA & FVC \\
\hline 1 & Dharmatala & $+2.47^{\circ} \mathrm{C}$ & $+2.43^{\circ} \mathrm{C}$ & $\begin{array}{l}+0.33> \\
\text { mean ISA }\end{array}$ & $\begin{array}{c}-0.32< \\
\text { mean FVC }\end{array}$ \\
\hline 2 & Garden Reach & $+4.05^{\circ} \mathrm{C}$ & $+0.71^{\circ} \mathrm{C}$ & $\begin{array}{l}+0.21> \\
\text { mean ISA }\end{array}$ & $\begin{array}{c}-0.18< \\
\text { mean FVC }\end{array}$ \\
\hline 3 & $\begin{array}{c}\text { Kalighat- } \\
\text { Tollygunge }\end{array}$ & $+1.72^{\circ} \mathrm{C}$ & $+0.68^{\circ} \mathrm{C}$ & $\begin{array}{l}+0.16> \\
\text { mean ISA }\end{array}$ & $\begin{array}{c}-0.14< \\
\text { mean FVC }\end{array}$ \\
\hline
\end{tabular}

Table 6. List of high risk locations in Kolkata

These areas urgently need landscaping with increase in vegetation cover. Adaptive planning needs to be incorporated in these zones to mitigate UHI intensity and size. The roofs, walls of the buildings here can be used for vertical gardening, green façade and green roof creation. The analysis suggested stronger UHI effects for summer season, at night time. Simultaneous sampling from large number of points with higher accuracy sensors will help to generate night time LST surface of better resolution. The methodology to utilize satellite data for providing 
valuable support in land management strategies has been described. Modified land system architecture should be of priority to management committee for developing sustainable urban societies.

\section{ACKNOWLEDGEMENTS}

Authors would like to thank Shubham Maurya, Anubhav Tiwari, Prabhat Kumar, Piyush Kumar Singh, Prakash Singh, Pradeep Singh, Saptak Banerjee, Upasana Datta and Shantanab Datta for their support in in-situ night time LST data collection.

\section{REFERENCES}

Abd El-Kawy, O.R., Rød, J.K., Ismail, H.A., Suliman, A.S., 2011. Land use and land cover change detection in the western Nile delta of Egypt using remote sensing data. Applied Geography 31, 483-494. https://doi.org/10.1016/j.apgeog.2010.10.012

Carlson, T.N., Arthur, S.T., 2000. The impact of land use - land cover changes due to urbanization on surface microclimate and hydrology: a satellite perspective. Global and Planetary Change 25, 49-65. https://doi.org/10.1016/S0921-8181(00)00021-7

Connors, J.P., Galletti, C.S., Chow, W.T.L., 2012. Landscape configuration and urban heat island effects: Assessing the relationship between landscape characteristics and land surface temperature in Phoenix, Arizona. Landscape Ecology 28, 271283. https://doi.org/10.1007/s10980-012-9833-1

Dutta, K., Basu, D., Agrawal, S., 2018. Temporal and spatial analysis of urban heat island using landsat satellite data: Two Indian case studies, in: ISPRS Annals of the Photogrammetry, Remote Sensing and Spatial Information Sciences. pp. 71-78. https://doi.org/10.5194/isprs-annals-IV-5-71-2018

Fasona, M., Omojola, A., 2009. Land cover change and land degradation in parts of the southwest coast of Nigeria. African journal of Ecology 47, 30-38. https://doi.org/10.1111/j.13652028.2008.01047.x

Grover, A., Singh, R., 2015. Analysis of Urban Heat Island (UHI) in Relation to Normalized Difference Vegetation Index (NDVI): A Comparative Study of Delhi and Mumbai. Environments 2, 125-138. https://doi.org/10.3390/environments2020125

Kolokotsa, D., Psomas, A., Karapidakis, E., 2009. Urban heat island in southern Europe: The case study of Hania, Crete. Solar Energy 83, 1871-1883. https://doi.org/10.1016/j.solener.2009.06.018

NASA, 2011. Landsat 7 Handbook.

Oke, T.R., 1976. The distinction between canopy and boundarylayer urban heat Islands. Atmosphere 14, 268-277. https://doi.org/10.1080/00046973.1976.9648422

Pauleit, S., Ennos, R., Golding, Y., 2005. Modeling the environmental impacts of urban land use and land cover change - A study in Merseyside, UK. Landscape and Urban Planning 71, 295-310. https://doi.org/10.1016/j.landurbplan.2004.03.009

Punia, M., Joshi, P.K., Porwal, M.C., 2011. Decision tree classification of land use land cover for Delhi, India using IRSP6 AWiFS data. Expert Systems with Applications 38, 55775583. https://doi.org/10.1016/j.eswa.2010.10.078
Qin, Z., Karnieli, A., Berliner, P., 2001. A Mono-window algorithm for retrieving land surface temperature from Landsat TM data and its application to the Israel-Egypt border region. International Journal of Remote Sensing 22, 3719-3746. https://doi.org/10.1080/01431160010006971

Rasul, G., Ibrahim, F., 2017. Urban Land Use Land Cover Changes and Their Effect on Land Surface Temperature: Case Study Using Dohuk City in the Kurdistan Region of Iraq. climate 5, 1-18. https://doi.org/10.3390/cli5010013

Rossi, F., Bonamente, E., Nicolini, A., Anderini, E., Cotana, F., 2016. A carbon footprint and energy consumption assessment methodology for UHI-affected lighting systems the areas. Energy and Buildings 114, 96-103. https://doi.org/10.1016/j.enbuild.2015.04.054

Setianto, A., Triandini, T., 2013. Comparison of Kriging and Inverse Distance Weighted (IDW) interpolation methods in lineament extraction and analysis. Journal of Southeast Asian Applied Geology 5, 21-29. https://doi.org/10.22146/jag.7204

Sobrino, J.A., Raissouni, N., 2000. Toward remote sensing methods for land cover dynamic monitoring: Application to Morocco. International Journal of Remote Sensing 21, 353-366. https://doi.org/10.1080/014311600210876

Soltani, A., Sharifi, E., 2017. Daily variation of urban heat island effect and its correlations to urban greenery: A case study of Adelaide. Frontiers of Architectural Research 6, 529-538. https://doi.org/10.1016/j.foar.2017.08.001

Tan, J., Zheng, Y., Tang, X., Guo, C., Li, L., Song, G., Zhen, X. Yuan, D., Kalkstein, A.J., Li, F., Chen, H., 2010. The urban heat island and its impact on heat waves and human health in Shanghai. International Journal of Biometeorology 54, 75-84. https://doi.org/10.1007/s00484-009-0256-X

Tiangco, M., Lagmay, A.M.F., Argete, J., 2008. ASTER-based study of the night-time urban heat island effect in Metro Manila. International Journal of Remote Sensing 29, 2799-2818. https://doi.org/10.1080/01431160701408360

Van Beers, W.C.M., Kleijnen, J.P.C., 2003. Kriging for interpolation in random simulation. Journal of the Operational Research Society 54, 255-262. https://doi.org/10.1057/palgrave.jors.2601492

Vanderstraete, T., Goossens, R., Ghabour, T.K., 2006. The use of multi-temporal Landsat images for the change detection of the coastal zone near Hurghada, Egypt. International Journal of Remote Sensing 27, 3645-3655. https://doi.org/10.1080/01431160500500342

Weng, Q., 2001. A remote sensing-GIS evaluation of urban expansion and its impact on surface temperature in the Zhujiang Delta, China. International Journal of Remote Sensing 22, 19992014. https://doi.org/10.1080/713860788

Weng, Q., Firozjaei, M.K., Sedighi, A., Kiavarz, M., Alavipanah, S.K., 2019. Statistical analysis of surface urban heat island intensity variations: A case study of Babol city, Iran. GIScience and Remote Sensing 56, 576-604. https://doi.org/10.1080/15481603.2018.1548080

Zhao, X., Huang, J., Ye, H., Wang, K., Qiu, Q., 2010 Spatiotemporal changes of the urban heat island of a coastal city 
in the context of urbanisation. International Journal of Sustainable Development and World Ecology 17, 311-316.

https://doi.org/10.1080/13504509.2010.490333 